\title{
Examining the Relationship between Binge Eating and Coping Strategies and the Definition of Binge Eating in a Sample of Spanish Adolescents
}

\author{
Susana Sierra Baigrie and Serafín Lemos Giráldez \\ Universidad de Oviedo
}

The present study had two major goals: to explore the relationship between binge eating and coping strategies in a sample of Spanish adolescents and to examine the adolescents' concept of binge eating. Two hundred and fifty-nine adolescents from a secondary school completed the Adolescent Coping Scale (ACS; Frydenberg \& Lewis, 1993) and the Bulimic Investigatory Test, Edinburgh (BITE; Henderson \& Freeman, 1987), as well as additional questions regarding the binge-eating episodes. The results show that the adolescents who reported binge eating used more avoidance coping strategies than those who did not engage in this behavior. Adolescents took into account mainly the amount of food eaten when defining a binge with few of them mentioning loss of control in their descriptions. The results of the study have implications for the prevention of this behavior. The development of constructive ways for solving daily problems and coping with stressors may be a possible prevention strategy for this behaviour in adolescence.

Keywords: binge, coping strategies, avoidance

\begin{abstract}
Este estudio tenía dos objetivos principales: explorar la relación entre los atracones de comida y las estrategias de afrontamiento en una muestra de adolescentes españoles y examinar el concepto que tienen los adolescentes de atracones. Una muestra de 259 adolescentes de una escuela secundaria rellenaron el ACS y el BITE, así como preguntas adicionales sobre los episodios de atracones. Los resultados muestran que los adolescentes que informaban del comportamiento de atracones empleaban más estrategias evitativas de afrontamiento que los que no realizaban este tipo de comportamiento. Al definir un atracón, los adolescentes consideraban principalmente la cantidad de comida consumida y pocos mencionaban la pérdida de control en sus descripciones. Los resultados del estudio tienen implicaciones para la prevención de este comportamiento. El desarrollo de formas constructivas para resolver los problemas cotidianos y afrontar los estresores puede ser una estrategia de prevención de este comportamiento en adolescentes.

Palabras clave: atracón, estrategias afrontamiento, evitación
\end{abstract}

Correspondence concerning this article should be addressed to Susana Sierra Baigrie, Facultad de Psicología, Universidad de Oviedo, Plaza Feijóo, s/n, 33003 Oviedo (Spain). E.mail: susisierrab@telecable.es 
Binge eating is a central feature in the diagnosis of two of the recognized eating disorders: bulimia nervosa and the more recently proposed binge-eating disorder (DSM-IV-TR, 2000). It is also fairly prevalent in people with another major eating disorder, anorexia nervosa, who engage in episodes of overeating after periods of strict dietary restraint (de la Serna, 1998). Binge eating is also present in individuals who have a partial or sub-threshold eating disorder namely eating patterns that do not meet the full diagnostic criteria for a major eating disorder but that are nevertheless very distressing for the person (Chamay-Weber, Narring \& Michaud, 2005). However, binge eating is not restricted to individuals with eating disorders. Previous research studies have found that this behavior is more prevalent than was formerly believed and has been reported in clinical samples as well as in the general population (Ackard, Neumark-Stainer, Store, \& Perry, 2003; Croll, Neumark-Sztainer, Store, \& Ireland, 2002; Vanderlinden, Grave, Vandereycken, \& Noorduin, 2001). It is even more common in samples of overweight and obese populations (Didie \& Fitzgibbon, 2005). In fact, it is estimated that approximately $70 \%$ of people who report problems with binge eating are obese (Amigo, 2003).

Binge eating is a relatively frequent behavior among adolescents. The frequency reported by adolescents varies in different studies but it is in general terms quite significant. Ackard et al. (2003) conducted a study in public middle and high schools in Minnesota that focused on the presence of overeating in adolescents and found that this behavior was reported by $17.3 \%$ of the girls and $7.8 \%$ of the boys in their sample. The youngsters who reported binge eating had a higher body mass index (BMI), lower self-esteem, depressive symptoms, and were less satisfied with their body image compared to those who did not report binge eating. They also had a higher risk for suicide than the adolescents who did not engage in this behavior. Vanderlinden et al. (2001) found that $41 \%$ of the women aged 14 to 25 who participated in their study reported binge eating at least once with $15 \%$ of these women indicating that they had daily binges. The authors were quite surprised at the high rate of binge eating in a nonclinical sample. Similarly, in another study by Aljadir and Liprie (1999), 51\% of the participants (adolescents aged 10 to 15 ) reported at least one episode of binge eating in the previous week. Especially interesting was the high rate of boys $(46 \%)$. They also found that binge eating was negatively correlated with age, with the highest rates of binge eating in the 10-year-old group. The results of this study suggest that binge eating may begin at an earlier age than was previously believed.

The study of the prevalence of binge eating in Spain is very scarce. In fact, we were unable to find any epidemiological studies on this behavior. We can only make approximations on the frequency of this conduct based on the prevalence of eating disorders in general and especially on that of bulimia nervosa. Furthermore, the number of studies focused on binge eating is very limited. However, its study is important as there are several long-term consequences for the person who binge eats. Binge eating can be considered a risk factor for the development of a full blown eating disorder, such as bulimia nervosa or binge eating disorder (Didie \& Fitzgibbon, 2005). These disorders cause important damage to a person's physical, psychological and social well-being (Johnson, Cohen, Kasen, \& Brook, 2002). Moreover, binge eating, not followed by compensatory methods, causes important weight gain and obesity in the long-run which is associated to a great number of physical and psychological health risks. The compensatory methods that in some cases follow a binge-eating episode also have important damaging effects on a person's health. Hence, as binge eating is a symptom and a possible antecedent to two major eating disorders also present in the general population, especially in overweight and obese individuals, it can be considered a behavior that can threaten a person's well-being. For this reason, it is especially important to identify the factors associated to the development of this unhealthy eating pattern in young adolescents who have not yet developed an eating disorder.

Numerous studies have analyzed the factors involved in binge eating (e.g., Benjamín \& Wulfert, 2005; Fischer, Anderson, \& Smith, 2004; Ghaderi, 2003; McLaren, Gauvin, \& Steiger, 2001; Stice, Presnell, \& Spangler, 2002; Stickney, Miltenberger, \& Wolf, 1999; Vanderlinden et al., 2001). Some of the factors identified as precursors to binge-eating episodes are a depressive mood, excessive preoccupation with body image, anxiety, hostility, boredom and dietary restraint (Stickney et al., 1999).

Over the years several theories have been proposed to explain binge eating. Among these we can cite the restraint hypothesis, the binge-purge hypothesis, the set point hypothesis and theories that consider binge eating an affective disorder or an addiction (Beebe, 1994; Fairburn, 1995).

An interesting and novel explanation for binge eating was offered by Heatherton and Baumeister (1991) with the escape model. For these authors, binge eating acts as an escape from negative self-awareness. Binge eating is viewed as a way of focusing all the attention on immediate sensations thus, turning attention away from themselves and the negative feelings they are experimenting. The model sees bingeing as an escape mechanism from a dysphoric mood. We believe this model to be an interesting explanation for binge eating although more research needs to be done regarding many aspects of the underlying theory. Following this theory, it is possible that adolescents who do not have the appropriate skills to be able to solve and confront their daily problems in a constructive manner may also try to escape from the negative feelings and thoughts surrounding the unresolved problems through an escape mechanism, for example through binge eating. Therefore, we consider that adolescents with a greater tendency to use avoidance coping strategies would be more prone to binge eating. 
Along the same line, the relationship between the different coping strategies used and eating pathology has been the focus of a great number of studies (e.g., Ball \& Lee, 2002; Denisoff, 2000; García-Grau, Fusté, Miró, Saldaña, \& Bados, 2004; Mayhew \& Edelmann, 1989; Schwarze, Oliver, \& Handal, 2003; Wolff, Crosby, Roberts, \& Wittrock, 2000; Yager, Rorty, \& Rosotto, 1995). One of these studies compared the coping strategies used by recovered and non-recovered women with bulimia nervosa. The non-recovered women with bulimia used less productive and fewer coping strategies than the recovered women (Yager et al., 1995). In another study (Garcia-Garu et al., 2004), self-blame, which is a scale of the intropunitive avoidance dimension in the ACS, was the strategy with the strongest link to the predisposition to eating disorders. Similarly, Mayhew and Edelmann (1989) also found that higher scores on the Eating Disorders Inventory (EDI) were associated to lower self-esteem, more irrational thinking, decreased use of cognitive and behavioral coping strategies and increased use of avoidance coping. Schwarze et al. (2003) centered their study on the link between coping and binge eating in particular. Their results were similar to those of previous research showing that the female undergraduate students in their study who had problems with binge eating were more prone to using avoidance coping strategies than the women who did not binge eat. But when depression was statistically controlled they did not find a significant difference between the two groups. Furthermore, Wolf et al. (2000) in another study did not find a clear link between binge eating and the coping strategies used. The women in their study who binge ate did not differ from the ones who did not binge eat in the number of coping strategies used, but did differ in that they used avoidance coping more frequently. There is a need to clarify the role of coping strategies in the development or maintenance of binge eating.

The present study had two major objectives. On the one hand, we were interested in further examining the link between binge eating and the coping strategies used by adolescents who have not yet developed an eating disorder. Adolescents cope with their daily stresses and problems with strategies that they have learnt and improved over the years (Williams \& McGillicuddy-De Lisi, 2000). The lack of skills to cope with difficulties may create a situation of greater stress which in some cases could compel the adolescent to try to escape from it through an avoidance mechanism such as binge eating. Regarding the coping strategies used, we hypothesized that adolescents who binge would use fewer problem-focused coping strategies and more avoidance coping strategies than the adolescents who do not binge eat.

On the other hand, another aspect we were interested in was the adolescents' definition of a binge. Previous research studies have suggested that the community's understanding of a binge may differ from the way the diagnostic manuals define the term (e.g., Diagnostic and Statistical Manual of Mental Disorders, American Psychiatric Association, 1992; Beglin \& Fairburn, 1992). Therefore, there could be considerable disagreement between the non-professional use of the term binge and that of the professionals who use the DSM-IV (1994) definition. This is important to explore because there could be poor understanding between patients and professionals assessing their eating problems. In the present study, we were interested in knowing what the adolescents considered to be a binge and examine if there is any difference in the variables mentioned by the adolescents who binge eat and those who do not. We hypothesized that the adolescents who binge eat would mention more variables in their definitions than those who do not binge eat.

\section{Method}

\section{Participants}

A total of 259 secondary school students from Avilés (Asturias, northern Spain) participated in the study. The ages ranged from 12 to 21 years (mean age 14.72 years) with $58.3 \%$ boys and $41.7 \%$ girls. Table 1 shows the sample distribution by age and gender.

\section{Measures}

In addition to indicating their age and gender, the participants were asked to complete the following instruments:

Table 1

Sample Distribution by Age and Gender

\begin{tabular}{clcc}
\hline Age Group & Boys & Girls & Total \\
\hline $12-13$ & $48(32 \%)$ & $36(33.3 \%)$ & $84(32.6 \%)$ \\
$14-15$ & $48(32 \%)$ & $41(38 \%)$ & $89(34.5 \%)$ \\
$16-17$ & $40(26.7 \%)$ & $23(21.3 \%)$ & $63(24.4 \%)$ \\
$\geq 18$ & $14(9.3)$ & $8(7.4 \%)$ & $22(8.5 \%)$ \\
\hline
\end{tabular}

Note. One participant did not indicate his age 
The Bulimic Investigatory Test, Edinburgh (BITE; Henderson \& Freeman, 1987) is a self-report questionnaire used to evaluate the presence and severity of bulimic symptomatology. It is composed of 33 items divided into two different subscales: a symptom subscale (30 items) (for example: "Are you worried about not being able to control how much you eat?") and a severity subscale (3 items) ("frequency of fasting", "methods for losing weight", and "frequency of binge eating"). This questionnaire has been widely used in different studies on binge eating and other eating pathology. The test's reliability has been analyzed by Rivas, Bersabé and Jiménez (2004) in a sample of Spanish adolescents. These authors consider the BITE to be a relative valid test for the evaluation of bulimic symptomatology.

The Adolescent Coping Scale (ACS; Frydenberg \& Lewis, 1993) is a self-report inventory to assess the coping strategies used by adolescents between the ages of 12 and 18. It consists of a total of 80 items, one of which is an open-ended question. The rest of the items are statements that reflect different ways of coping and that are rated on a 5-point Likert scale. It evaluates 18 different coping strategies that have been previously conceptually and empirically identified. These 18 coping strategies can be grouped into four different major dimensions: positive and effortful action (for example: "I try to solve what is causing the problem"), hedonist positive action (for example: "I do sports"), intropunitive avoidance (for example "I feel guilty") and introversion ("I avoid being with others"). The 18 scales for the coping strategies have been shown to have construct validity and factorial analysis results support the existence of these dimensions (Frydenberg \& Lewis, 1993).

Additional open-ended questions to obtain more information about the binge-eating episodes were completed by the participants. These questions allowed the adolescents to define binge eating in their own words.

\section{Procedure}

Participants were recruited from a public secondary school in Avilés and the study took place during the school schedule. The study was completely anonymous and voluntary.

Each group took approximately an hour to complete the study.

Table 2

Percentage of Participants Who Reported Binge Eating at Least Once by Age and Gender

\begin{tabular}{ccrr}
\hline Age Group & Boys & Girls & Total \\
\hline $12-13$ & $11(23.4 \%)$ & $8(23.5 \%)$ & $19(23.5 \%)$ \\
$14-15$ & $11(22.9 \%)$ & $10(24.4 \%)$ & $21(23.6 \%)$ \\
$16-17$ & $23(57.5 \%)$ & $8(34.8 \%)$ & $31(49.2 \%)$ \\
$\geq 18$ & $11(78.6 \%)$ & $3(37.5 \%)$ & $14(63.6 \%)$ \\
\hline
\end{tabular}

\section{Data Analysis}

All statistical analyses were done using the 12.0 version of the SPSS program for Windows. For group comparisons with respect to interval variables, multivariate analyses of variance (MANOVA) were performed to determine global differences between the groups. When Wilks' $\lambda$ was significant $(p \leq .05)$, univariate analyses of variance (ANOVA) were then conducted to determine in which variables the groups were different.

When we had to compare groups in categorical variables, differences were considered significant.

\section{Results}

To determine the rate of binge eating in our sample we analyzed the participants' answers to question 24 of the BITE "Have you ever binged on food?" To this question $33.2 \%$ (85) of the adolescents answered yes $(37.3 \%$ of the boys and $27.4 \%$ of the girls). The percentages of the participants who reported binge eating at least once are shown in Table 2.

Table 2 shows how the percentage of participants who indicated binge eating at least once increases with age $(\chi=$ 23.587, $p=.000$ ). However, we did not find a significant difference between the percentage of boys and girls who reported binge eating $(\chi=2.786 ; \mathrm{p}=0.095)$.

In order to know with what frequency the adolescents who reported binge eating have these episodes, we examined the participants' answers to question 27 of the BITE "With what frequency do you binge eat?" The results show that $64.4 \%$ of these adolescents reported having the binge-eating episodes rarely, $20.7 \%$ reported binge eating once a month, $5.7 \%$ reported binge eating once a week, $4.6 \%$ reported binge eating 2-3 times per week, $2.3 \%$ reported daily binges and $2.3 \%$ reported binge eating 2-3 times a day. There were no significant differences in the responses given due to gender $(\chi=5.139, p=.40)$ or to age $(\chi=17.660, p=.281)$. Table 3 shows the frequencies of binge eating for boys and girls.

Regarding the presence of problems with binge eating, the mean score on the BITE was 4.42 points $(S D=4.33)$ with a maximum score of 23 points and a minimum of zero. chi-square analyses were performed. When $p \leq .05$, the 
Table 3

Frequency of Binge Eating by Gender

\begin{tabular}{lccc}
\hline Frequency of binge eating & Boys & Girls & Total \\
\hline Rarely & $32(57.1 \%)$ & $24(77.4 \%)$ & $56(64.4 \%)$ \\
Once a month & $14(25 \%)$ & $4(12.9 \%)$ & $18(20.7 \%)$ \\
Once a week & $3(5.4 \%)$ & $2(6.5 \%)$ & $5(5.7 \%)$ \\
$2-3$ times a week & $3(5.4 \%)$ & $1(3.2 \%)$ & $4(4.6 \%)$ \\
Daily & $2(3.6 \%)$ & 0 & $2(2.3 \%)$ \\
$2-3$ times a day & $2(3.6 \%)$ & 0 & $2(2.3 \%)$ \\
\hline
\end{tabular}

Henderson and Freeman (1987) consider a BITE score under 10 points as indicative of no problem with eating behavior, a score between 10 and 20 points as indicative of abnormal eating patterns (from 15 to 20 points warns us of the presence of a possible sub-threshold bulimia nervosa) and a score higher than 20 points constitutes altered eating patterns with a possible bulimia nervosa. In the current study, there were only four cases with a score of 20 or greater and 25 cases with scores between 10 and 20 points. Most of the adolescents had less than 10 points on the BITE.

Table 4 shows the mean scores and standard deviations on the BITE for the different age groups for girls and boys. Although the mean BITE scores increase with age, the MANOVA comparing the mean BITE scores and the severity scores for the different age groups proved to be not significant (Wilks' $\lambda=0.971, p=.275$ ). With respect to gender, another MANOVA revealed no significant differences between girls and boys in the mean BITE scores and the severity scores (Wilks' $\lambda=0.985, p=.15$ ).
Coping strategies and the presence of binge eating. To test the hypothesis regarding the relationship between coping strategies and binge eating we compared the coping strategies used by the adolescents who reported binge eating and those who did not. The sample was divided into two groups: those who had indicated binge eating at least once (adolescents who answered affirmatively to question 24 of the BITE) and those who had never had a binge (those who answered negatively to the same question). We compared their mean scores on the four dimensions of coping measured by the ACS (positive and effortful coping, intropunitive avoidance, positive hedonist coping, and introversion). For this purpose, a MANOVA was conducted and the results showed significant differences between the groups (Wilks' $\lambda=$ $0.951, p=.013)$. The ANOVAs revealed that the differences were due to the avoidance coping dimension $(\mathrm{F}=5.96, p$ $=.015)$. Table 5 shows the results of the ANOVAs conducted comparing the mean scores for both groups on the four dimensions of the ACS.

Table 4

Means and Severity Scores (and both Standard Deviations) for the BITE by Age Group and Gender

\begin{tabular}{cccr}
\hline Age Group & Boys & Girls & Total \\
\hline \multirow{2}{*}{$12-13$} & $3.89(4.65)$ & $4.02(4.06)$ & $3.95(4.38)$ \\
& $0.56(1.20)$ & $0.88(1.72)$ & $0.70(1.44)$ \\
$14-15$ & $3.68(3.08)$ & $5.56(5.40)$ & $4.55(4.38)$ \\
& $0.62(1.51)$ & $1.19(1.93)$ & $0.88(1.73)$ \\
$16-17$ & $3.70(3.48)$ & $6.08(5.35)$ & $4.57(4.37)$ \\
& $1.07(1.80)$ & $1.60(2.23)$ & $1.27(1.97)$ \\
$\geq 18$ & $6.50(4.18)$ & $3.50(2.67)$ & $5.41(3.92)$ \\
& $1.21(1.47)$ & $0.50(0.76)$ & $0.95(1.29)$ \\
\hline
\end{tabular}

Table 5

ANOVA Results Comparing the Means on the Dimensions of Coping of Adolescents with and without Problems with Binge Eating

\begin{tabular}{lccccc}
\hline Dimension of Coping & Binge-eating $(n=85)$ & No binge-eating $(n=170)$ & $F$ & $p$ & $\eta^{2}$ \\
\hline Positive and effortful coping & $271.08(38.7)$ & $277.00(59.05)$ & 0.70 & $n s$ \\
Positive-hedonist coping & $457.34(76.28)$ & $441.48(70.16)$ & 2.73 & $n s$ \\
Introversion & $204.61(44.99)$ & $193.91(41.35)$ & 3.57 & $n s(0.06)$ & .011 \\
Avoidance coping & $133.33(35.69)$ & $121.60(36.40)$ & 5.96 & 0.015 & .023 \\
\hline
\end{tabular}


Table 6

ANOVA Results Comparing the Means on the Dimensions of Coping of Adolescents with and without Problems with Binge Eating

\begin{tabular}{|c|c|c|c|c|c|}
\hline Dimension of Coping & Binge-eating $(n=29)$ & No binge-eating $(n=229)$ & $F$ & $p$ & $\eta^{2}$ \\
\hline Positive and effortful coping & $260.55(43.44)$ & $276.73(53.74)$ & 2.43 & $n s$ & .009 \\
\hline Positive-hedonist coping & $435.34(67.50)$ & $449.02(72.98)$ & 0.92 & $n s$ & .004 \\
\hline Introversion & $229.34(52.67)$ & $193.18(39.51)$ & 19.88 & .000 & .072 \\
\hline Avoidance coping & $159.55(32.27)$ & $121.31(34.77)$ & 31.62 & 0000 & .110 \\
\hline
\end{tabular}

The binge-eating group had higher mean scores on three of the four dimensions of coping (introversion, positive hedonist coping and avoidance coping) although only the difference in the dimension of avoidance coping proved to be significant. Although not statistically significant, the mean score for the positive and effortful coping dimension was lower in the binge-eating group.

Furthermore, we compared the coping strategies used by the adolescents who have problems with binge eating (based on the BITE scores) and those who do not have any problems with this behavior. For this analysis, we divided the sample into two groups, this time based on the cut-off scores for the presence of problems with binge eating established by Henderson and Freeman (1987) (i.e., BITE $\geq 10$ ). The MANOVA conducted revealed significant differences between the two groups (Wilks' $\lambda=0.829, p=.000$ ) in the coping strategies used. The ANOVAs showed that the differences were significant in two of the four dimensions of coping: avoidance coping and introversion. Table 6 shows the ANOVA results with the mean scores on the four dimensions of coping.

The adolescents with binge eating problems have higher mean scores on the two dimensions of coping: introversion and avoidance coping. In addition, there were no significant differences in the positive dimensions of coping between the groups.

The adolescents' definition of binge eating: analysis of the variables mentioned (amount, time and loss of control). Participants were asked to define with their own words binge eating and to give an example of a binge-eating episode. Their answers were then categorized and given a value ( 0 to 3 ) depending on whether they mentioned none, one, two or the three variables included in the DSM-IV (1994) definition of a binge: amount eaten, time, and loss of control. Most of the participants who answered (72.2\%) described binge eating solely in terms of amount eaten, $14.9 \%$ also mentioned time in their definition and only $12.9 \%$ described binge eating using the three variables (amount, time and loss of control). No significant differences were found in the number of variables mentioned by the adolescents who reported binge eating and those who did not $(\chi=3.53, p>.05)$. However, there was a significant difference in the number of variables mentioned by girls and boys $(\chi=12.56, p=.006)$, with the girls taking into account the three variables more often than the boys. In addition, there were also significant differences due to the age group $(\chi=21.03, p=.013)$.

\section{Discussion}

One of the two main purposes of the present study was to explore the link between coping skills and binge eating. Based on the results found in previous studies (Ball \& Lee, 2002; Denisoff, 2000; García-Grau et al., 2004; Mayhew \& Edelmann, 1989; Schwarze et al., 2003; Wolf et al., 2000; Yager et al., 1995), it was expected that the adolescents who binge eat would use more avoidance coping strategies (unproductive coping) and fewer problem-focused strategies (positive coping) compared to the adolescents who do not binge eat. The results confirmed part of the hypothesis; the adolescents who binge eat use avoidance coping more frequently than those who do not binge eat. However, the results showed that there were no differences between the adolescents who binge eat and those who do not with respect to the problem-focused (positive) coping strategies used, that is, both groups use the positive coping strategies with similar frequencies, failing to confirm the second part of the hypothesis. This means that both groups have developed positive coping strategies and probably use them in a similar manner. Perhaps the adolescents who binge have more difficulties dealing or coping with certain kinds of problems or emotions. It would be interesting to determine which are the situations associated with the use of avoidance coping strategies in adolescents who binge eat and compare the strategies used by those who do not.

These results are consistent with past research (Ball \& Lee, 2002; García-Grau et al., 2004; Schwarze et al., 2003; Wolf et al., 2000) regarding the higher use of avoidance coping skills in individuals who binge eat compared to those who do not. However, in the present study, as well as in the study by Wolf et al. (2000), there was no difference found in the frequency of the positive strategies used between the adolescents who binge eat and those who do not, showing that they do not use more avoidance coping strategies instead of positive coping strategies but that they use a greater number of coping strategies in general. A more exhaustive analysis of the types of avoidance coping strategies used by the adolescents who binge eat without yet having a diagnosable eating disorder may help determine the types of avoidance initially used by the adolescents who might have problems with binge eating in the future. Prevention of binge eating problems could focus on these unproductive coping strategies by helping the adolescent find positive 
ways of coping and therefore avoiding the development of unhealthy habits such as drug abuse or binge eating. These results are consistent with Heatherton and Baumeister's theory on binge eating. It is possible that some adolescents do not know how to deal with certain types of problems, creating a more stressful situation from which they will try to escape by focusing their attention on immediate sensations, for example through binge eating.

The other main objective of the present study was to examine the adolescents' definition of binge eating. It is interesting to point out the clear tendency to describe eating binges solely in terms of the large amount of food eaten. The other two variables that according to the DSM-IV (1994) definition of binge eating must be present, time and loss of control, were mentioned by only a small group of adolescents. A study at the University of Manitoba (SierraBaigrie, 1997) precisely examined the effect of these three variables (amount eaten, time, and loss of control) that appear in the DSM-IV (1994) in the identification of eating episodes as binges. The results showed that amount eaten had a significant effect on the ratings with no effect found for time. Furthermore, loss of control interacted with both time and amount eaten. Therefore, loss of control appears to play an important role in the determination of a binge. However, in the present study there were very few adolescents who mentioned loss of control in their definition of binge eating. Contrary to what was hypothesized there was no difference in the number of variables mentioned by those who had had binges and those who did not. This could possibly be due in part to the adolescents' immaturity in verbalizing different behaviors or feelings focusing on objective factors (such as amount) as opposed to more subjective variables (such as loss of control). It would be interesting to determine which variables are taken into account when rating one's own eating episodes as neither in the study by Sierra-Baigrie (1997) nor in the present study were the participants asked to do so. Perhaps when defining what a binge is people take into account more objective variables with the more subjective variables being more important when rating one's own behavior.

With respect to the rate of binge eating the results indicate that the percentage of adolescents who binge eat increases with age, with the highest rates in the 18 and older age group, with $63.6 \%$ of these reporting the presence of this behavior. Although the difference between the reported rates of binge eating between girls and boys was not statistically significant, it is interesting to point out that the percentage of boys who reported binge eating increased considerably after the age of 16 with respect to the rates found in girls. A possible explanation for this increase in boys with respect to girls could be the fact that after a certain age girls are usually more preoccupied with their weight and figure than boys, which could make them control their eating behavior much more. On the other hand, girls may feel worse after a binge-eating episode which could also explain this difference as it is possible that the girls will take more measures to avoid these eating binges. Future research could further explore the factors that may be causing this difference.

In the present study, the overall percentage of adolescents who reported having had a binge was higher in boys than in girls which is different from what was found in previous studies with higher percentages in girls than in boys (Ackard et al.,2003; Aljadir \& Liprie ,1999). In fact, some studies on eating pathology do not include males in their samples (e.g., Stice et al., 2002; Vanderlinden et al., 2001). However, the high rates of binge eating among boys found in the study by Aljadir and Liprie (1999) as well as in the present study, warn us of the importance of including both boys and girls in the studies in order to obtain samples that are more representative of the population who binge eats and improve our understanding of this behavior.

With respect to the frequency with which the adolescents in the present study reported binge eating, most of the adolescents indicated that they had these eating binges rarely or once a month, with very few of them reporting daily binges. These frequencies were not surprising considering that the sample was recruited from a non-clinical population with few cases found with abnormal patterns of eating behavior (those with a BITE score of 10 or more points).

The present study has some important limitations. First, the sample size was not very large and it consisted of participants all recruited from the same secondary school. Therefore, it cannot be considered a representative sample of the adolescent population of our region. A wider and more varied sample with participants recruited from secondary schools from different urban and rural areas of the region would improve the external validity of the study. Another limitation to the present study was the low percentage of participants between 16 and 17, and especially that of participants over 18 in comparison with the other age groups. This is due to the fact that in this centre there were fewer students attending high school. In addition, the presence of students over 18 in high school is expected to be limited. Regardless, the tests used for statistical analyses were quite robust and therefore the difference in the group sizes probably did not have an effect on the results. Anyhow, it would be convenient to increase the number of participants in those age groups to avoid this problem. Finally the most important limitation is pinpointed by the findings regarding the adolescents' definition of binge eating. The results show how the participants defined binge eating taking into account mainly the amount eaten and failing to mention loss of control or time in their definitions. This brings doubts as to whether we have a true measure of binge eating as we used one direct question to determine the adolescents who binge eat. If adolescents mainly take into account the amount eaten it could somewhat inflate the rate of adolescents who report binge eating as we may also be including some adolescents who have episodes of overeating without loss of control. 
Regardless of the aforementioned limitation, the results of the current study show how binge eating, defined mainly as overeating, is a fairly frequent behavior among adolescents and is associated to the use of avoidance coping strategies. These findings have important implications with respect to the prevention of binge eating and therefore the development of eating disorders. One possible means of prevention for binge eating drawn from the results of this study could be to focus on the adolescents' coping skills helping them develop healthy and productive ways of coping with their problems and to identify when they use avoidance coping strategies, and showing them ways of dealing with the feelings or the situations that trigger an escape mechanism.

There are also implications drawn from the findings regarding the adolescents' definition of binge eating. As we had said previously, there is a clear difference between the adolescents' definition of binge eating and the definition used by clinicians and researchers. This brings doubts about whether studies that measure binge eating without explicitly mentioning the three variables considered by the DSM-IV obtain a true measure of binge eating. Adolescents may be referring to overeating episodes as binge eating episodes which may falsely identify adolescents as binge eaters who in reality are not. It may be necessary to either explain what binge eating is according to the diagnostic manuals or formulate questions which explicitly consider the three variables mentioned in the definition. It is also possible that adolescents take more into account objective variables when defining binge eating and more subjective variables when rating their own episodes. Nevertheless, it is important to further explore which variables are taken into account when rating one's own eating episodes as binges.

\section{References}

Ackard, D.M., Neumark-Sztainer, D., Story, M. \& Perry, C. (2003). Overeating among adolescents: Prevalence and associations with weight-related characteristics and psychological health. Pediatrics, 111, 67-74.

American Psychiatric Association. (1994). Diagnostic and statistical manual of mental disorders (4th ed.). Washington, DC: Author.

American Psychiatric Association. (2000). Diagnostic and statistical manual of mental disorders (4th ed. Text Revision). Washington, DC: Author.

Amigo, I. (2003): La delgadez imposible. Barcelona: Paidós Ibérica S.A.

Aljadir, L.P. \& Liprie, M.L. (1999). High rate of binge-eating among young adolescents. Journal of the American Dietetic Association, 99 (Suppl.), A50

Ball, K., \& Lee, C. (2002). Psychological stress, coping, and symptoms of disordered eating in a community sample of young Australian women. International Journal of Eating Disorders, 31, 71-81.
Beebe, D.W. (1994). Bulimia nervosa and depression: A theoretical and clinical appraisal in light of the binge-purge cycle. British Journal of Clinical Psychology, 33, 259-276.

Beglin, S.J., \& Fairburn, D.M. (1992). What is meant by the term binge. American Journal of Psychiatry, 149, 123-124.

Benjamin, L., \& Wulfert, E. (2005). Dispositional correlates of addictive behaviours in college women: Binge eating and heavy drinking. Eating Behaviors, 6, 197-209.

Chamay-Weber, C., Narring, F., \& Michaud, P. (2005). Partial eating disorders among adolescents: A review. Journal of Adolescent Health, 37, 416-426.

Croll, J., Neumark-Sztainer, D., Story, M., \& Ireland, M. (2002). Prevalence and risk and factors related to disordered eating behaviours among adolescents: Relationship to gender and ethnicity. Journal of Adolescent Health, 31, 166-175.

Corstorphine, E., Mountford, V., Tomlinson, S., Waller, G., \& Meyer, C. (2007). Distress tolerance in the eating disorders. Eating Behaviors, 8, 91-97.

De la Serna, I. (1998): Comer no es un placer. Madrid: Litofinter, S.A.

Denisoff, E. (2000). Life experiences, coping and weight preoccupation in young adult women. Canadian Journal of Behavioral Science, 32, 97-103.

Didie, E., \& Fitzgibbon, M. (2005). Binge eating and psychological distress: Is the degree of obesity a factor? Eating Behaviors, 6, 35-41.

Fairburn, C.G. (1995). Overcoming binge eating. New York: Guilford Press.

Fischer, S., Anderson, K.G., \& Smith, G.T. (2004). Coping with distress by eating or drinking: Role of trait urgency and expectancies. Psychology of Addictive Behaviors, 18, 269-274.

Frydenberg, E., \& Lewis, R. (1993). Manual: The Adolescent Coping Scale. Melbourne: Australian Council for Educational Research (Spanish translation: Escalas de afrontamiento para adolescentes (Manual). Madrid: Ediciones TEA, 1993).

Gahderi, A. (2003). Structural modeling analysis of prospective risk factors for eating disorder. Eating Behaviors, 3, 387-396.

Garcia-Grau, E., Fusté, A., Miró, A., Saldaña, C., \& Bados, A. (2004). Coping style and vulnerability to eating disorders in adolescent boys. European Eating Disorders Review, 12, 6167.

Heatherton, T.F., \& Beumeister, R.F. (1991). Binge eating as escape from self-awareness. Psychological Bulletin, 110, 86-108.

Henderson, M., \& Freeman, C. P. (1987). A self-rating scale for bulimia. The "BITE". British Journal of Psychiatry, 150, 18-24.

Johnson, J.G., Cohen, P., Kasen, S., \& Brook, J. S. (2002). Eating disorders during adolescence and the risk for physical and mental disorders during early adulthood. Archives of General Psychiatry, 59, 545-552.

Mayhew, R., \& Edelmann, J. (1989). Self-esteem, irrational beliefs and coping strategies in relation to eating problems in a nonclinical population. Personality and Individual Differences, 10, 581-584.

McLaren, L., Gauvin, L., \& Steiger, H. (2001). A two-factor model of disordered eating. Eating Behaviors, 2, 51-65. 
Rivas, T., Bersabé, R., \& Jiménez, M. (2004). Fiabilidad y validez del Test de Investigación Bulímica de Edimburgo (BITE) en una muestra de adolescentes españoles. Psicología Conductual, $12,447-461$.

Schwarze, N.J., Oliver, J.M. \& Handal, P.J. (2003). Binge eating as related to negative self-awareness, depression, and avoidance coping in undergraduates. Journal of College Student Development, 44, 644-652.

Sierra-Baigrie, S. (1997). Judgements of videotaped eating episodes as binges: Effects of DSM-IV criteria, size and duration of episode, and loss of control over eating. Submitted as requirement for the degree of Bachelor of Arts (Honours) in Psychology (University of Manitoba).

Stice, E., Presnell, K., \& Spangler, D. (2002). Risk factors for binge eating-onset in adolescent girls. A two year prospective investigation. Health Psychology, 21, 131-138.

Stickney, M.I., Miltenberger, R.G., \& Wolff, G. (1999). A descriptive analysis of factors contributing to binge eating. Journal of Behavior Therapy and Experimental Psychiatry, 30, 177-189.
Vanderlinden, J., Grave, R.D., \& Vandereycken, C.N. (2001). Which factors do provoke binge-eating? An exploratory study in female students. Eating Behaviors, 2, 79-83.

Williams, K., \& McGillicuddy-De Lisi, A. (2000). Coping strategies in adolescents. Journal of Applied Developmental Psychology, 20, 537-549.

Wolff, G.E., Crosby, R.D., Roberts, J.A., \& Wittrock, D.A. (2000). Differences in daily stress, mood, coping, and eating behaviour in binge eating and nonbinge eating women. Addictive Behaviors, 25, 205-216.

Yager, J., Rorty, M., \& Rosotto, E. (1995). Coping styles differ between recovered and nonrecovered women with bulimia nervosa, but not between recovered women and non-eatingdisordered control subjects. Journal of Nervous and Mental Disease, 183, 86-94.

Received January, 23, 2007 Revision received August, 27, 2007 Accepted September, 19, 2007 